\title{
COLABORAÇÃO ENTRE DIREÇÃO ESCOLAR E PROFESSORES COM FOCO NA APRENDIZAGEM DISCENTE
}

\author{
http://dx.doi.org/10.5902/2318133861846
}

\author{
Francisca Risolene Fernandes ${ }^{1}$ \\ Francisca Genifer Andrade de Sousa ${ }^{2}$ \\ Lia Machado Fiuza Fialho ${ }^{3}$
}

\begin{abstract}
Resumo
Por meio deste texto apresenta-se resultado de pesquisa pela qual objetivou-se compreender o papel do diretor escolar frente às demandas que ultrapassam o âmbito burocrático-administrativo da gestão e que suscitam relações colaborativas com os professores no tocante ao trabalho desenvolvido em sala de aula. Com abordagem qualitativa, do tipo estudo de caso, a pesquisa utilizou questionários aplicados com diretores e professores vinculados à Secretaria Municipal de Educação de Horizonte/CE. Os dados foram submetidos à análise de conteúdo e emergiram três categorias: 1) práticas colaborativas com foco na aprendizagem escolar, que elucidou a ausência de companheirismo entre a direção e o corpo docente; 2) responsabilização dos professores pelo rendimento dos alunos; 3 ) diferentes sentidos atribuídos aos diagnósticos das aprendizagens dos alunos. Concluiu-se que os professores são considerados os principais encarregados pelo rendimento dos alunos e que a colaboração da gestão em sala de aula é esporádica, pois os diretores priorizam as atividades burocráticas com ações verticalizadas que utilizam a avaliação como mecanismo de controle e responsabilização docente.
\end{abstract}

Palavras-chave: diretor escolar, aprendizagem, autoritarismo.

\section{COLLABORATION BETWEEN SCHOOL DIRECTORS AND TEACHERS WITH A FOCUS ON DISCENT LEARNING}

\begin{abstract}
Through this text, a research result is presented, aiming to understand the role of the school principal despite demands that go beyond the bureaucratic-administrative scope of management and that raise collaborative relationships with teachers regarding the work developed in the classroom. With a qualitative approach, of the case study type, the research used questionnaires applied with principals and teachers linked to the Municipal Education Department of Horizonte/CE. The data were submitted to content analysis and three categories emerged the following: 1) collaborative practices with a focus on school learning, which elucidated the lack of companionship between the management and faculty; 2) teachers' accountability for student performance; 3 ) different meanings attributed to the students' learning diagnoses. It was concluded that the teachers are considered the main ones responsible for the students' performance and that the collaboration of the management in the classroom is sporadic, since the directors prioritize the bureaucratic activities with verticalized actions that use the evaluation as a mechanism of control and teacher responsibility.
\end{abstract}

Key-words: school director, learning, authoritarianism.

\footnotetext{
${ }^{1}$ Secretaria de Educação da Prefeitura Municipal de Horizonte/CE, Brasil. E-mail: profarisolenefernandes@gmail.com.

2 Universidade Estadual do Ceará, Brasil. E-mail: geniferandrade@yahoo.com.br.

3 Universidade Estadual do Ceará, Brasil. E-mail: lia fialho@yahoo.com.br. 


\section{Introdução}

diretor da escola é protagonista na gestão escolar, a qual pode ser entendida como o processo de "gerir a dinâmica do sistema de ensino como um todo e a coordenação das escolas em específico, afinado com as diretrizes e políticas educacionais públicas" (Lück, 2015, p. 35), com vistas a assegurar a melhor organização do ambiente educacional. Para Libâneo (2015) esse esforço deve ser entendido como a ação de mobilização dos procedimentos com vistas à consecução dos objetivos educativos, o que aponta para a implementação da gestão democrática participativa nas escolas, oportunizando à comunidade escolar de se manifestar e participarem ativamente da construção e execução do projeto político-pedagógico. Importa, pois, a comunidade escolar - pais, alunos, professores, técnicos educacionais, dentre outros profissionais escolares -, colaborar para a eficiência da própria gestão com o mote de otimizar a aprendizagem integral dos discentes, já que cabe à escola, junto à família, garantir a formação dos estudantes (Brasil, 1988).

No Brasil a noção de gestão escolar pautada na parceria entre os sujeitos responsáveis pela tarefa educativa teve respaldo com a Constituição Federal de 1988, sendo mais tarde reforçada pela LDB. A partir desses instrumentos legais passou-se a veicular a compreensão de gestão associada à participação democrática, em contraposição à gestão gerencial, que vigorou mais enfaticamente até o início da década de 1990 (Oliveira; Carvalho, 2018). Nesse novo molde são priorizadas ações gestoras focadas na qualidade dos processos educativos incluindo, dentre outras nuances, o desenvolvimento da aprendizagem em sala de aula, considerada elemento de suma importância.

Exercer a gestão democrática na escola é uma atividade desafiante para o núcleo gestor, principalmente para o diretor, que até a última década do século passado costumava centralizar o poder decisório e, mais recentemente, foi convidado a atuar de modo democrático, considerando o diálogo horizontal para tomar as decisões pertinentes à instituição escolar (Paro, 2015). Ante a essa nova compreensão de gestão a comunidade escolar se apresenta não apenas como receptora de normas e decisões, mas como protagonista na constituição de encaminhamentos educacionais, participando ativamente dos conselhos escolares, opinando sobre os assuntos educativos e fiscalizando o andamento da gestão.

O diretor da escola, além das competências em administração institucional, precisa ter conhecimento acerca dos aspectos pedagógicos para que possa atuar junto à comunidade escolar, como um educador-gestor corresponsável pela aprendizagem dos alunos (Libâneo, 2015). Tal modo a gestão democrática supera a ação puramente burocrática-administrativa na qual não cabe 0 autoritarismo, ao contrário, sugere ricas possibilidades para a negociação e colaboração multiprofissional.

Ante a tais considerações sobre a gestão escolar democrática e participativa, questiona-se: como se estabelecem as relações entre diretores e professores nas escolas de ensino fundamental do município de Horizonte/CE? O objetivo do estudo foi compreender o papel do diretor escolar frente às demandas que ultrapassam o âmbito burocrático-administrativo da gestão e que suscitam relações colaborativas com os professores no tocante ao trabalho desenvolvido em sala de aula para qualificar a aprendizagem dos alunos. 
O objeto de estudo são as narrativas de diretores e professores, coletadas mediante questionário, de escolas públicas de ensino fundamental do município de Horizonte/CE, região metropolitana de Fortaleza.

\section{Metodologia}

Trata-se de uma pesquisa de abordagem qualitativa (Minayo, 1994), já que avulta as subjetividades de diretores e professores vinculados à Secretaria Municipal de Educação de Horizonte/CE, ao realçar as suas percepções e gerar visibilidade às minúcias não passíveis da devida apreensão em estudos quantitativos influenciados pelo universo das operacionalizações de variáveis. É do tipo estudo de caso único, tendo em vista que considerou um único lócus de investigação, ou seja, diretores e professores de apenas um município cearense. Essa escolha foi amparada em Yin (2001), que defende a realização de estudos de caso por esta vertente se constituir em "uma investigação empírica que investiga um fenômeno contemporâneo dentro de seu contexto da vida real, especialmente quando os limites entre o fenômeno e o contexto não estão claramente definidos" (p. 32), o que oportuniza uma pesquisa qualitativa mais aprofundada.

O lócus de coleta de dados foi o Instituto Federal de Educação, Ciência e Tecnologia situado em Horizonte/CE, local onde são desenvolvidas as formações continuadas voltadas para o público atuante no campo da educação desse município. Foi nesse IFCE onde os professores e os gestores em formação foram convidados a colaborar com o estudo mediante resposta a um questionário, aplicado em setembro de 2018. Ao total foram contatados, pessoalmente, 18 diretores e 14 professores. Desse universo 15 diretores e 10 professores aceitaram participar do estudo.

Foram elaboradas duas versões do referido questionário, uma para os diretores e outra para os professores, ambas compostas por cinco indagações abertas. 0 instrumento aplicado aos gestores inqueria o seguinte: 1) Na sua opinião, qual é a função do diretor e do professor? 2) O diretor deve apoiar o trabalho dos professores? Caso positivo, como? 3) Como você compreende os diagnósticos de leitura e escrita realizados na escola onde atua? 4) A partir dos resultados dos diagnósticos, é traçada alguma medida voltada para aprimorar a aprendizagem dos discentes? 5) Há outros agentes que colaboram com o ensino escolar em sala de aula, além dos professores? Aos professores as questões foram: 1) Como você se sente enquanto profissional da educação? 2) Após a realização dos diagnósticos de aprendizagem das turmas que você leciona, você define alguma ação focalizada para o desenvolvimento da aprendizagem dos estudantes? 3) Você conta com a colaboração de outro profissional no tocante ao trabalho realizado em sala de aula? Caso positivo, de quem? 4) O diretor da instituição onde você atua auxilia no aspecto pedagógico efetivado em sala de aula? 5) $\mathrm{Na}$ sua opinião, qual o papel do diretor escolar?

O conteúdo coletado a partir dos questionários foi tratado mediante análise de conteúdo (Bardin, 2006), porquanto, seguiu-se às seguintes fases: organização da análise; codificação; categorização; tratamento dos resultados, inferência e interpretação dos resultados. Inicialmente foi efetivada leitura e releitura flutuante do material, seguida da pré-análise, a partir da qual foram agrupados os assuntos mais recorrentes. 
Posteriormente houve a codificação das unidades de sentido e a categorização, que facultou a agrupação das informações similares, que por sua vez, "reúnem um grupo de elementos [...] sob um título genérico, agrupamento esse efetuado em razão dos caracteres comuns destes elementos" (Bardin, 2006, p. 117).

No ato de análise do conteúdo do material coletado mediante questionário foram seguidos os seguintes critérios: juntaram-se as informações que apresentavam similaridade, agruparam-se os construtos afins e, por último, reuniram-se as temáticas de acordo com os grupos temáticos. Esse procedimento pode ser mais bem compreendido a partir da análise do seguinte quadro, que explicita os grupos temáticos e os descritores que os compuseram.

Quadro 1 -

Grupos temáticos e unidades de sentido.

\begin{tabular}{|lll|l|}
\hline \multicolumn{1}{|c|}{ Grupos temáticos } & \multicolumn{2}{|c|}{ Unidades de sentido } \\
\hline $\begin{array}{l}\text { Práticas colaborativas com foco na } \\
\text { aprendizagem escolar }\end{array}$ & $\begin{array}{l}\text { Supervisão. Direção. Gestão. } \\
\text { Resultados. Programa Mais } \\
\text { Educação. Auxílio. Suporte. Reforço. } \\
\text { Leitura e escrita. Audiência de leitura. } \\
\text { Satisfação. }\end{array}$ \\
\hline $\begin{array}{l}\text { Responsabilização do professor pelo } \\
\text { rendimento dos alunos em sala de aula }\end{array}$ & $\begin{array}{l}\text { Aprendizagem. Projeto. Estagiários. } \\
\text { Monitores. Gestão pedagógica. } \\
\text { Campo pedagógico. Prática em sala } \\
\text { de aula. Índice de aprendizagem. } \\
\text { Satisfação. }\end{array}$ \\
\hline $\begin{array}{l}\text { Sentidos atribuídos aos diagnósticos da } \\
\text { aprendizagem }\end{array}$ & $\begin{array}{l}\text { Avaliar. Acompanhar. Monitorar. } \\
\text { Reunião. Encaminhamentos. Novas } \\
\text { práticas. Metodologia. Controle. } \\
\text { Melhores resultados. }\end{array}$ \\
\hline
\end{tabular}

Fonte: autores (2020).

Em face do exposto as informações obtidas junto aos professores e diretores foram analisadas e unificadas em grupos a partir de uma frase aglutinadora, que agrupou as informações que apresentavam afinidade. Desse modo foram reunidas as informações sobre como vêm sendo desenvolvidas as práticas colaborativas entre professores e outros agentes com foco no aprendizado em sala de aula; às incumbências de cada profissional com essa tarefa; sobre as implicações dos diagnósticos de aprendizagem dos alunos na prática de professores e diretores. Esse percurso metodológico culminou na categorização, última etapa da análise de conteúdo, que orientou a discussão dos resultados.

\section{Resultados e discussão}

Efetivada a análise do conteúdo, resultaram três categorias: 1) práticas colaborativas com foco na aprendizagem escolar; 2) responsabilização do professor pelo rendimento dos alunos; 3) diferentes sentidos atribuídos aos diagnósticos da aprendizagem. Tendo em vista que a pesquisa é do tipo qualitativa e foca na qualidade da discussão dos 
conteúdos e não na quantificação dos achados, optou-se por apresentar e discutir os resultados a partir dos trechos considerados mais significativos das respostas dos sujeitos participantes. Dessa forma, algumas respostas foram suprimidas por não apresentarem representatividade, sendo elucidadas aquelas com maior relevância para o entendimento de cada uma das três categorias temáticas emergentes da análise de conteúdo, abordadas a posteriori.

\section{Categoria 1: práticas colaborativas com foco na aprendizagem escolar}

O modelo de gestão democrática, por vezes denominado gestão participativa, determina que os objetivos da escola, no que toca à formação do estudante, sejam alcançados a partir da colaboração de todos aqueles que se relacionam com o ambiente escolar, de modo que cabe à comunidade escolar o acompanhamento e a qualificação sistemática das atividades pedagógicas (Escudero; González, 1994; Lück, 2001). Nessa perspectiva não há um agente isolado que controla o andamento da instituição ou do aprendizado; todos dirigem e são dirigidos, avaliam e são avaliados, pois a gestão democrática descentralizou o poder (Lima, 2001) e diversos agentes - pais, familiares, professores, coordenadores, diretores, técnicos, etc. - são corresponsáveis pelo bom desempenho educacional e pela efetivação do principal objetivo da educação, que é a formação dos estudantes nos aspectos cognitivo, emocional, ético e cidadão (Brasil, 1988).

Uma vez que a figura do diretor centralizador foi modificada com a perspectiva da gestão democrática, os profissionais inseridos no ambiente escolar devem atuar de modo colaborativo com os professores que lecionam em sala de aula (Gatti, 2008). Dos dez professores pesquisados nove não mencionavam o diretor como uma pessoa que colaborava com o ensino e aprendizagem, secundarizando a importância do gestor na práxis educativa. Afirmaram receber ajuda de terceiros - pais, técnicos, estagiários e monitores - no processo de aprendizagem dos alunos, mencionando, majoritariamente, os profissionais do programa Mais Educação. O professor 10 identificou alguns dos agentes mais citados que colaboram com a prática dos professores em sala de aula: "Temos alguns funcionários da escola, pais de alunos, que fazem audiência de leitura, voluntários universitários que ficam na sala de aula com o professor, ajudando com os alunos que apresentam mais dificuldades, além do Programa Mais Educação".

O programa Mais Educação é uma iniciativa do governo federal com o escopo de otimizar a aprendizagem nas áreas de Português e de Matemática no ensino fundamental, a partir da ampliação da jornada escolar em alguns dias da semana. Nessa perspectiva os profissionais vinculados ao programa Mais Educação eram os que mais ajudavam os alunos nas suas dificuldades, seguidos dos pais de alunos, voluntários e outros funcionários da escola. O professor 5 acrescenta outros profissionais que colaboravam esporadicamente: "Às vezes tem a menina da secretaria, a estagiária, o digitador". No entanto, esse apoio difuso não é a realidade vivenciada por todos os docentes, já que cinco afirmaram não contar com nenhum apoio, além daqueles profissionais vinculados ao programa Mais Educação, a exemplo do professor 6, que informou: "não tenho quem me ajude. Da escola não. Conto somente com apoio do Mais Educação, que é à parte". 
Somente um professor mencionou a colaboração direta do diretor, explicando que este realiza audiências de leitura com os alunos, corroborando para o ensino da leitura e da escrita: "Minha diretora dava reforço para as crianças leitoras de letras, com planejamento e atividades, elaborados por ela" (professor 7). No entendimento dos docentes não é comum que os diretores atuem diretamente ou em parceria com os professores, com foco no suporte aos alunos no que se refere à aprendizagem, deixando essa atribuição, por vezes exclusivamente para os colaboradores do já referenciado programa de iniciativa Federal.

Dos 15 diretores participantes do estudo somente dois afirmaram atuarem junto aos professores em sala de aula mediante oferta de reforço aos estudantes, ainda assim tratase de uma ação pontual, como asseveraram os diretores 3 e 1, respectivamente: "eu ajudo o professor quando dá, não é sempre também"; "eu busco colaborar com reforço, mas são várias turmas e nem sempre é possível". Nota-se que somente esses dois diretores, mesmo incumbidos por outras atividades administrativas, tentavam fomentar suporte pedagógico aos professores em sala de aula, inclusive, ofertando momentos de reforço escolar aos alunos. Os demais, no máximo, envolviam-se no desenvolvimento de projetos para sanar os problemas de aprendizagem, mas estes seriam realizados pelos professores.

Importa destacar que apesar de a maioria dos diretores entrevistados não se sentirem corresponsáveis pela aprendizagem dos alunos em sala de aula, eles se preocupavam com o rendimento dos alunos e, alguns, inclusive, incentivam à realização de projetos que abarcam todos os agentes envolvidos com a atividade escolar, desde 0 bibliotecário à comunidade. $\mathrm{O}$ diretor 5 disse ter idealizado o Projeto Maleta Viajante: "o aluno leva para casa um livro dentro de uma pasta, que parece uma maleta, e escreve e desenha algo sobre ele, depois devolve e é a vez de outro aluno levar". O diretor 7 , por sua vez, informou que junto à bibliotecária da escola, sempre fica à frente de "aulas de campo quando possível, além dos encontros com o professor diretor de turma, de projetos de incentivos, gincanas e elogios para motivar os alunos em público". O diretor 13 mencionou sua participação em "rodas de leitura no recreio literário e em firmar parceria com as familias".

São variadas, portanto, as iniciativas listadas pelos diretores com foco no desenvolvimento da aprendizagem dos estudantes, principalmente no que tange à leitura e à escrita. Mesmo que o apoio da direção escolar seja crucial para a efetivação de uma atividade educativa, mais interessante ainda é quando há engajamento na sua concretização (Gobbi et al, 2020), o que não se consolida nesse caso, pois os projetos, mesmo que por vezes sejam idealizados pelos diretores, são executados por outros agentes, como os professores, os estagiários e os coordenadores, de modo que "o diretor, às vezes, faz alguma coisa, dar suporte a um evento, um projeto, mas ele não vai lá agir de fato. Sempre quem faz acontecer são outras pessoas" (professor 7). O professor 9 tenta resumir a participação diretor: "Uma atividade diferenciada que é proposta, uma gincana, uma aula de campo, por exemplo, o diretor vai, aparece, faz a fala para mediar; mas é o professor, o bibliotecário, o monitor quem faz tudo desde o início".

Os docentes alegaram sentirem-se pressionados: "sou feliz por propiciar às crianças uma descoberta no mundo letrado, mas também pressionado, porque são muitas as responsabilidades, muita pressão" (professor 10). Tal narrativa que explicita a sobrecarga 
dos professores, gerando, por vezes, desmotivação à classe docente, pode estar associada, de acordo com Freitas et al (2012), às demasiadas exigências postas ao profissional da educação, que nos últimos tempos tem sido impelido a atender aos interesses de entidades externas à realidade escolar, como agências de fomento e processos avaliativos em larga escala. Nessa direção o professor 6 destacou que "apesar dos desafios e cobranças, gosto de ser professor, mas, algumas vezes, me sinto só, desmotivado, mas quando vejo as coisas funcionando, dando certo, ganho novo fôlego". Observa-se, todavia, que esse cenário não pode ser considerado resultado da ausência de colaboração entre gestores e professores, até mesmo porque ambos estão imersos em um sistema que exige atuações profissionais específicas e demonstram tentar incansavelmente maneiras de superar as dificuldades dos alunos.

O fato é que os diretores, mesmo atentos à supervisão do setor pedagógico, não são protagonistas no que diz respeito à aprendizagem dos alunos, restando essa responsabilidade aos professores, que pontualmente são ajudados por outros sujeitos escolares, especialmente, os integrantes do programa Mais Educação. Por isso, quando são realizados diagnósticos para a sondagem acerca dos níveis de aprendizagem dos alunos, diretores e professores entendem os resultados de maneira diferenciada.

\section{Categoria 2: responsabilização do professor pelo rendimento dos alunos em sala de aula}

Mesmo que o compromisso pela garantia da aprendizagem dos alunos diga respeito a todos os profissionais da educação (Oliveira; Waldhelm, 2016), no que tange à dimensão pedagógica, esta é atribuída quase que exclusivamente aos professores, cabendo aos diretores "delegar tarefas, para que todo funcionário tenha ciência de sua função e dê conta de todas elas" (diretor 8), sendo a aprendizagem do aluno considerada uma função da incumbência do professor.

Não significa que o diretor não esteja atento à tarefa educativa, já que o diretor 4, mesmo não atuando junto aos professores, afirma estar sempre a par do que ocorre em sala de aula: "Eu conheço toda a realidade das turmas, quantos alunos precisam fazer intervenção, quantos precisam de uma atenção maior, quem está com problemas”. Nessa perspectiva esse diretor se comporta de modo vigilante ao trabalho docente (Gomes, 2015), supervisionando com o escopo de se informar acerca do andamento da escolarização da escola onde atua, no entanto, as mudanças práticas eram consideradas tarefas docente, pois garantir a aprendizagem do aluno era a principal atribuição do professor segundo os diretores.

Sobre a divisão de tarefas que predomina no ambiente escolar Castro (2009) afirma que, apesar de cada profissional ter a sua função específica, é fundamental que o grupo se mobilize em sintonia em prol da oferta da educação que garanta a formação do estudante, pois a fragilidade dessa parceria pode influir negativamente na trajetória escolar (Oliveira; Carvalho, 2018), já que sozinhos, muitas vezes, os professores não conseguem sanar as dificuldades dos alunos, que progridem às séries sem a aquisição dos conhecimentos necessários. Dessa maneira faz-se necessário que o diretor busque alternativas para corroborar com a aprendizagem dos alunos sob o intuito de amenizar essa realidade (Oliveira; Vasques-Menezes, 2018). Somente dois diretores afirmaram interferir na dimensão pedagógica de maneira direta, auxiliando no trabalho docente em 
sala de aula, mesmo que não tenha especificado como são as suas ações e com qual frequência as desenvolve: "sempre que possível, ajudo meus professores, participando dos reforços e com os professores em sala, auxiliando" (diretor 1).

Dos quinze diretores investigados treze entendem que a sua função é guiar a instituição, supervisionando todas as áreas, inclusive no que concerne ao âmbito pedagógico, conforme relatos seguintes: "a meu ver, o diretor é a mola mestra da instituição de ensino e, além de representá-la dentro e fora da instituição, é ele quem organiza a gestão pedagógica e também as tarefas administrativas" (diretor 11); "a função do diretor é mediar, gerir a instituição de ensino, conciliando a gestão financeira, gestão de pessoal e, o principal, gerir a parte pedagógica da instituição" (diretor 2); "cabe ao diretor cuidar de toda a escola, do pedagógico ao administrativo. Ser responsável por todas as crianças e pela parte burocrática da instituição" (diretor 15). Observa-se que há a compreensão de que ao diretor compete gerenciar todas as áreas da escola, inclusive a pedagógica, aquela que diz respeito ao desenvolvimento do ensino e da aprendizagem escolar (Franco, 2003). Por outro lado, na compreensão dos professores, eles não se envolvem suficientemente com o âmbito pedagógico, pois delegam essa atividade aos coordenadores.

Em conformidade com estudo desenvolvido por Oliveira e Carvalho (2018), averiguou-se nessa pesquisa que a atuação do diretor era majoritariamente controladora, tornando o ambiente escolar semelhante a um estabelecimento empresarial tradicional, onde existe um chefe e outros trabalhadores seguem a ele subjugados. Isso porque não havia um diálogo profícuo entre os gestores e professores para discutir os problemas de aprendizagem e elaborar coletivamente estratégias para superação das dificuldades. Quando uma turma ou parte dela não alcançava o rendimento esperado nos testes diagnósticos, o professor era inquirido acerca do fracasso na aprendizagem como o principal e quase exclusivo responsável por essa atividade.

Por isso mesmo, os diretores, ao versarem sobre a função do professor, por unanimidade, responsabilizaram este profissional por fazer com que os alunos aprendam, sendo silenciada a responsabilidade do diretor ou do núcleo gestor para o desenvolvimento da aprendizagem. $O$ comentário de três diretores exemplificam 0 exposto, no que concerne a responsabilidade atribuída ao professor: "Ensinar com amor às crianças e apresentar um bom resultado" (diretor 14); "Além de ser o ator principal do processo de ensino e aprendizagem, ele deve desempenhar uma série de tarefas no meio escolar para atingir um índice cada vez maior de aprendizagem" (diretor 5); "O professor deve transmitir o que lhe compete da melhor forma possível e deve fazer isso com muito amor e dedicação, sempre tentando assegurar a aprendizagem" (diretor 12). A responsabilidade com a aprendizagem do aluno e o bom resultado recai quase exclusivamente sobre a classe docente, não sendo mencionada a maneira com que 0 diretor exerce a sua função colaborativa, que além da administração, exige colaboração com aqueles profissionais (Alves; Franco, 2008).

Observou-se que os professores se sentiam pressionados para garantir a aprendizagem dos alunos, no entanto, já que eram bem fiscalizados, eles não se percebiam apoiados pelo núcleo gestor, pois cabia aos docentes, muitas vezes sozinhos, buscarem alternativas para tentar concretizar a aprendizagem, e estes se sentiam, por vezes, impotentes ante a uma realidade que não conseguiam modificar, já que, segundo $o$ 
diretor 6, o Programa Mais Educação, apesar de ajudar no reforço escolar dos alunos mais atrasados, não supria a deficiência e tantas outras lacunas que interferiam no rendimento escolar.

Observa-se que os diretores escolares ainda assumem postura administrativa centralizadora, contrariando os princípios da gestão escolar colaborativa, para a qual se faz necessária parceria entre todos os seguimentos educativos (Gomes, 2015), o que colabora para a implantação de projetos verticalizados que sobrecarregavam o professor (Saldanha; Nodari; Salvagni, 2017). Uma hipótese elaborada para justificar essa maneira autoritária de gerir a escola diz respeito ao fato de que os diretores não foram eleitos, não possuíam formação específica em gestão escolar e nem realizaram qualquer formação continuada nesse sentido antes de assumirem o cargo, sendo que a preparação profissional para esse ofício é crucial à boa organização escolar (Jardilino; Sampaio, 2019).

Para Libâneo (2015) a problemática da contratação de diretores descompromissados com a gestão colaborativa das escolas é reforçada pela ausência de processo seletivo para a escolha daqueles que ocupam esse cargo, muitas vezes escolhidos mediante "nomeação, que é o procedimento mais prejudicial à gestão democrática na escola” (p. 97), já que não se preocupa em verificar as competências dos profissionais responsabilizados por gerir o ambiente escolar. Na mesma direção, Paro (2015) afirma que a ausência de seleção para compor o núcleo gestor é um dos empecilhos que mais corrobora para que as escolas sejam geridas por sujeitos que se comportam como administradores e não demonstram compromisso com a aprendizagem dos estudantes, não agindo de modo a democratizar a gestão escolar. A despeito dessa realidade a escolha do diretor escolar deve ser imbuída pela responsabilidade com o campo educativo (Cária; Santos, 2014) e, por isso, Libâneo (2015) critica a nomeação arbitrária desses profissionais, pois essa prática atende aos interesses políticos e não contribui para o pleno desenvolvimento do ensino, uma vez que nesses moldes o diretor se exime de executar o seu papel como articulador da docência.

No que concerne à essa atribuição, os professores não percebem o gestor como articulador e parceiro, o que reafirma a postura centralizadora dos diretores, conforme relato do professor 3 , que elencou as seguintes responsabilidades do diretor escolar:

"Penso que o diretor deve ser aquele que abre e fecha a escola, que
acompanha sistematicamente cada turma, tentando sondar as
necessidades das turmas, conhece cada aluno, cada família, cada
funcionário e cada professor. Mas não é isso que a gente observa, porque
o diretor se volta muito mais para atividades burocráticas e não
acompanhada, de maneira individualizada e interventiva, os problemas que
aparecem em sala de aula."

Esse relato traduz a noção de gestão escolar associada ao controle e à supervisão dos demais profissionais. Em contrapartida os princípios da gestão escolar democrática preveem que, ao mesmo tempo em que o diretor atue como vigilante à prática docente, também acompanhe o desenvolvimento da aprendizagem dos alunos e os esforços do 
professor, dividindo a responsabilidade e estabelecendo relação de proximidade com a família e com os demais agentes educativos (Sousa; Pereira, 2020). O fracasso ou o sucesso no rendimento escolar devem ser considerados responsabilidade compartilhada entre os atores educacionais (Pereira; Ribeiro, 2017).

\section{Categoria 3: diferentes sentidos atribuídos aos diagnósticos da aprendizagem}

A prática de diagnosticar o nível da aprendizagem dos estudantes era realizada mensalmente em Horizonte/CE, sendo um momento no qual a Secretaria de Educação desse município visava, tanto a acompanhar o desenvolvimento dos alunos, quanto gerar material para que os profissionais da educação delineassem as suas práticas. Para os diretores foi consensual o entendimento de que "os diagnósticos realizados servem para nortear o nível de aprendizagem de cada turma e, dessa forma, programar algumas intervenções" (diretor 1), haja vista que essa é "uma ferramenta que ajuda a traçar metas e ações para acompanhar os rendimentos dos alunos e melhorar a prática pedagógica" (diretor 8).

Esses posicionamentos coadunam com o que defendem Gauthier, Bissonnette e Richard (2014), para os quais "o objetivo de avaliar os aprendizados é verificar se os alunos são capazes de reconstruir o que eles aprenderam durante as atividades de aprendizado (tarefas fontes) e atividades de avaliação (tarefas alvos)" (p. 234), por isso, na concepção de Luckesi (2008), a partir dos resultados dos diagnósticos, toda a comunidade escolar, inclusive o diretor, deve se reunir para traçar estratégias de acompanhamento e reforço na sala de aula e extra sala, para que seja possível alcançar melhores resultados.

Ademais, a avaliação proporciona um indicativo de aprendizagem, cabendo à direção escolar investir, a partir desses dados, na produção dos resultados almejados (Luckesi, 2008), conforme enunciado pelo professor 3 ao se referir às iniciativas tomadas pela direção de suas escolas a partir dos resultados dos diagnósticos: "A direção organiza, dentro do programa Mais Educação, uma turma só com alunos que necessitam de um tempo a mais na escola. Isso acontece no contraturno, possibilitando que os alunos tenham um apoio especial sem perder o contato com a professora e com os colegas". Ainda que as avaliações servissem, majoritariamente, para identificar os alunos com maior dificuldade de aprendizagem e o programa Mais Educação ter sido a principal medida interventiva, professores e diretores não atribuíam os mesmos sentidos para essas avaliações diagnósticas, pois, para a maior parte dos diretores eles serviam para traçar um perfil dos alunos e das classes no que concerne ao nível de aprendizagem. Já para os docentes, para além disso, serviam para fiscalizar e controlar os professores e não se revestiam em ações práticas que realmente colaborassem com o tralho em sala de aula, já que o Mais Educação era oferecido no contraturno.

Apenas o professor 10 inferiu que "após o diagnóstico inicial, o núcleo gestor sentase com os professores no planejamento, faz uma curva do conhecimento dos alunos e, a partir daí, já decidiam sobre a parceria para o apadrinhamento dos que estão com dificuldades de aprendizagem". Ou seja, somente um professor mencionou uma análise pormenorizada dos resultados, culminando em intervenções pensadas e elaboradas conjuntamente. Os demais professores alegam sentirem-se pressionados e responsabilizados pela aprendizagem não satisfatória dos alunos. 
Oliveira e Vasques-Menezes (2018) explicam que o diálogo entre gestão e corpo docente é uma iniciativa não apenas relevante, mas condizente às responsabilidades do diretor, essencial para a efetivação de uma gestão democrática e participativa e para o bom desenvolvimento educacional como um todo. No entanto, nem sempre os diagnósticos culminavam em práticas colaborativas, pois era corriqueiro que o diretor decidisse sozinho como os professores deveriam desenvolver as suas práticas, tecendo orientações, sem que houvesse diálogo nos momentos de reunião, conforme averígua-se nos relatos a seguir: "A minha diretora chama todos os professores para conversar depois dos resultados [do diagnóstico], mas é mais para chamar a atenção da gente, dizer no que a gente precisa mudar" (professor 9); "Eu vejo o meu diretor sempre fazendo reunião com os professores com o intuito de repreendê-los. Colaborar de fato, nunca vi" (professor 6); "Os diretores que tive até hoje dizem o que é para a gente fazer. Falam sobre metodologia, sobre conteúdos que devemos abordar, estratégias de ensino" (professor 4).

Os diretores, em unanimidade, concordaram com a necessidade de realização de diagnósticos mensais e, ao contrário dos professores, não expressaram sentirem-se pressionados. Todos mencionaram que utilizam os resultados para cobrar novas estratégias pedagógicas por parte dos docentes em sala de aula e dos monitores do programa Mais Educação: "Vou indicando, prescrevendo atividades diversificadas por nível" (diretor 11); "Vejo o trabalho conjunto ao projeto Mais Educação" (diretor 1); "Sugiro atividades lúdicas que envolvem jogos pedagógicos" (diretor 7); "Cobro a audiência de leitura e simulados" (diretor 13); "Busco o reforço escolar no contraturno ao que o aluno estuda" (diretor 15). Essas ações visam a resolver o problema do baixo rendimento escolar, pois os diretores acreditam que após os diagnósticos, os professores devem modificar as suas práticas, para então dar conta de solucionar o problema de aprendizagem dos alunos.

Observa-se que os diretores orientam verbalmente os professores e monitores, os culpabilizando implicitamente pelo fracasso dos alunos, atribuindo os resultados deficitários à práxis incipiente do professor. $O$ diretor 11 explicou o que faz com os diagnósticos: "eu vou mediando e definindo como os professores devem agir para que a situação melhore, porque cabe ao professor mudar as suas aulas, senão bons resultados não serão alcançados". Percebe-se que o diretor tenta impor uma mudança na prática docente, no entanto, na maioria das vezes, com orientações verticalizadas que não valorizam o trabalho previamente realizado.

Em muitos casos, ao invés da cooperação, era reafirmada a atuação de diretores numa perspectiva controladora e até antidemocrática (Gobbi et al, 2020), pois alguns se portam como autoridades máximas no ambiente escolar, exigindo dos demais obediência. Essa conduta é prejudicial ao processo de avaliação dos estudantes, pois o ideal é que os envolvidos com a docência busquem considerar a avaliação como um diagnóstico discutível que pode ser utilizado como base para o desenvolvimento de uma parceira em prol do desenvolvimento da aprendizagem (Ferreira Filho, 2020) e, na mesma direção, aponte para a atuação conjunta de todos os indivíduos que interagem no ambiente escolar (Paro, 2015). Com efeito, as avaliações diagnósticas não podem se transformar em momentos de tensão para os professores do município de Horizonte/CE, tampouco serem utilizadas para responsabilização dos docentes pelo insucesso dos estudantes, ao 
contrário, precisa ser redimensionada na sua finalidade com o mote de fortalecer a articulação não apenas entre diretor e professor, mas com toda a comunidade escolar em prol do sucesso pedagógico.

\section{Considerações finais}

A pesquisa partiu da inquietação acerca de como se efetiva a relação entre a direção escolar e os professores no que concerne à aprendizagem dos estudantes. Para responder a esta problemática o estudo foi desenvolvido com o objetivo de compreender o papel do diretor frente às demandas que ultrapassam a direção do ambiente escolar e que suscitam relações colaborativas com os professores no trabalho desenvolvido em sala de aula para qualificar a aprendizagem dos alunos.

Desenvolveu-se uma pesquisa de abordagem qualitativa, do tipo estudo de caso, que envolveu 25 colaboradores - 15 diretores e 10 professores - vinculados à Secretaria Municipal de Educação de Horizonte/CE, cidade localizada na região metropolitana de Fortaleza/CE. Como instrumento de coleta de dados foram utilizados questionários abertos acerca do trabalho desenvolvido por esses profissionais no âmbito escolar, realçando experiências colaborativas para qualificar a aprendizagem dos alunos. As respostas aos questionários foram discutidas a partir da técnica da análise de conteúdo, na qual as informações afins foram agrupadas em três categorias: 1) práticas colaborativas com foco na aprendizagem escolar; 2) responsabilização pelo rendimento dos alunos em sala de aula; 3) sentidos atribuídos aos diagnósticos da aprendizagem.

Sobre as práticas colaborativas voltadas para o desenvolvimento da aprendizagem dos estudantes verificou-se que os professores são considerados os principais responsáveis pelo rendimento dos alunos e que quando os alunos apresentam dificuldades na aprendizagem há auxílios pontuais e esporádicos de alguns agentes envolvidos com a educação escolar, em especial, dos monitores do projeto Mais Educação. No entanto, o apoio dos diretores é insipiente, pois esses profissionais assumem posturas administrativas não consoantes aos princípios da gestão escolar democrática e colaborativa, ao priorizar as atividades burocráticas e ações verticalizadas. Ainda, quando os gestores buscam colaborar com os professores, a ajuda é na elaboração de projetos a serem desenvolvidos majoritariamente pelos professores, muitas vezes sem o devido diálogo. Ante a essa conjuntura os professores se sentem fiscalizados e cobrados, especialmente após a divulgação dos resultados das avaliações diagnósticas, e não percebem a gestão como parceira na superação dos problemas cotidianos.

A segunda categoria - responsabilização pelo rendimento dos alunos em sala de aula - explicitou que os diretores culpabilizam os professores quando o rendimento da sua classe não é diagnosticado a contento. Percebe-se que os gestores informam realizar um acompanhamento do trabalho do professor, no entanto, estes últimos se consideram fiscalizados e não devidamente amparados, já que há um olhar regulador que não é assistido com intervenções práticas dialogadas. Esse posicionamento verticalizado devese ao fato de os diretores entenderem que a sua função é gerir a instituição educativa, 
não sendo necessário se envolver diretamente com o âmbito pedagógico, por esta ser a principal responsabilidade do professor. Ademais, o fato de os diretores assumirem tal função sem formação específica, por meio de indicação política, corrobora com a adoção de concepções autoritárias e centralizadoras.

A terceira categoria, que tratou sobre os sentidos atribuídos aos diagnósticos da aprendizagem dos estudantes, realizados pela prefeitura de Horizonte/CE, com vistas a nortear a prática educativa, constatou que gestores e professores não percebiam a avaliação em larga escala da mesma maneira. Os primeiros entendiam ser importante acompanhar o trabalho do professor e o andamento da escola, enquanto os últimos acreditavam que a avaliação causava constrangimento, fiscalização e culpabilização do professor, inclusive, gerando sentimento de impotência e desanimo. Os resultados, enquanto indicativos de um diagnóstico no que concerne à aprendizagem, não eram utilizados para reunir docentes, gestores e demais membros da comunidade escolar num diálogo profícuo acerca do enfrentamento dos problemas identificados. Ao contrário, servia como mecanismo de controle e cobrança.

Conclui-se que a relação entre a direção escolar e os professores, no que concerne à aprendizagem dos estudantes, é verticalizada e pouco participativa, pois os diretores, na maioria dos casos, não estabeleciam vínculos horizontais e colaborativos para qualificar a aprendizagem dos alunos, ao contrário, delegavam essa atividade a outros atores, como os monitores do programa Mais Educação, eximindo-se dessa responsabilidade e secundarizando o diálogo como meio de mediar o desenvolvimento de projetos coparticipativos e sinérgicos à comunidade escolar.

\section{Referências}

ALVES, Maria Tereza Gonzaga; FRANCO, Creso. A pesquisa em eficácia escolar no Brasil: evidências sobre o efeito das escolas e fatores associados à eficácia escolar. In: BROOKE, Nigel; SOARES, José Francisco (orgs.). Pesquisa em eficácia escolar: origem e trajetórias. Belo Horizonte: UFMG, 2008, p. 482-500.

BARDIN, Laurence. Análise de conteúdo. Lisboa: Edições 70, 2006.

BISSONNETTE, Steve; RICHARD, Mário; GAUTHIER, Clermont; BOUCHARD, Carl. Quelles sont les stratégies d'enseignement efficaces favorisant les apprentissages fondamentaux auprès des élèves en difficulté de niveau élémentaire? Résultats d'une méga-analyse. Revue de recherche appliquée sur l'apprentissage, v. 3, 2010, p. 1-35.

BRASIL. Constituição da República Federativa do Brasil. Diário Oficial da União, 5 de outubro de 1988.

CÁRIA, Neide Pena; SANTOS, Mileide Pereira. Gestão Democrática e escola: limites e desafios. Revista de Gestão e Avaliação Educacional, Santa Maria, v. 3, n. 6, 2014, p. 2741.

CASTRO, Rosana de Freitas. Fatores associados ao desempenho escolar na $4^{\mathrm{a}}$ série do ensino fundamental. In: LORDÊLO, José Albertino Carvalho; DAZZANI, Maria Virgínia (org.). Avaliação educacional: desatando e reatando nós. Salvador: UFBA, 2009, p. 26595.

ESCUDERO Juan Manuel; GONZÁLEZ, Maria Tereza Professores y escurela: ¿Hacir uma reconversion de los centros y la función docente? Madrid: Pedagógicas, 1994. 
FERREIRA FILHO, Luciano Nery. O projeto de avaliação diagnóstica da rede pública estadual do Ceará - Análise dos descritores críticos em Matemática. Rev. Pemo, Fortaleza, v. 2, n. 3, 2020, p. 1-16.

FREITAS, Luiz Carlos de; SORDI, Maria Regina Lemes; MALAVASI, Maria Márcia Sigrist; FREITAS, Helena Costa Lopes de. Avaliação educacional: caminhando pela contramão. Petrópolis: Vozes, 2012.

GATTI, Bernardete. Relatório do seminário internacional "construindo caminhos para o sucesso escolar". In: GATTI, Bernardete A (org.). Construindo caminhos para o sucesso escolar. Brasília: Unesco, 2008, p. 9-26.

GOBBI, Beatriz Christo; LACRUZ, Adonai José; AMÉRICO, Bruno Luiz; ZANQUETTO FILHO, Hélio. Uma boa gestão melhora o desempenho da escola, mas o que sabemos acerca do efeito da complexidade da gestão nessa relação? Ensaio: Avaliação e Políticas Públicas em Educação, Rio de Janeiro, v. 28, n. 106, 2020, p.198-220.

FRANCO, Maria Amélia Santoro. Pedagogia como ciência da educação. Campinas: Papirus, 2003.

GOMES, Ana Valeska Amaral. Gestão democrática no plano nacional de educação. In: Gomes, A. V. A.; Britto, Tatiana Feitosa de (orgs.). Plano nacional de educação: construção e perspectivas. Brasília: Câmara dos Deputados, 2015, p. 141-166.

JARDILINO, José Rubens Lima; SAMPAIO, Ana Maria Mendes. Desenvolvimento profissional docente: Reflexões sobre política pública de formação de professores. Educação \& Formação, Fortaleza, v. 4, n. 1, 2019, p. 180-194.

LIBÂNEO, José Carlos. Organização e gestão da escola: teoria e prática. Porto Alegre: Heccus, 2015.

LIMA, Licínio. A escola como organização educativa. São Paulo: Cortez, 2001.

LUCKESI, Cipriano. Avaliação da aprendizagem: componente do ato pedagógico. São Paulo: Cortez, 2004.

LÜCK, Heloísa. A escola participativa: o trabalho do gestor escolar. São Paulo: Vozes, 2001.

LÜCK, Heloísa. Gestão educacional uma questão de paradigmática. São Paulo: Vozes, 2015.

MINAYO, Maria Cecília de Sousa. Pesquisa social: teoria, método e criatividade. Petrópolis: Vozes, 1994.

OliveIRA, Ana Cristina Prado de; CARVALHO, Cynthia Paes de. Gestão escolar, liderança do diretor e resultados educacionais no Brasil. Rev. Bras. Educ., Rio de Janeiro v. 23, 2018, p. 1-18.

OLIVEIRA, Ana Cristina Prado de; WALDHELM, Andrea Paula Souza. Liderança do Diretor, clima escolar e desempenho dos alunos: qual a relação? Ensaio: Avaliação e Políticas Públicas em Educação, Rio de Janeiro, v. 24, n. 93, 2016, p. 824-44.

OLIVEIRA, Ivana Campos; VASQUES-MENEZES, Ione. Revisão de literatura: o conceito de gestão escolar. Cadernos de Pesquisa, São Paulo, v. 48, n. 169, 2018, p. 876-900.

PARO, Vitor Henrique. Diretor escolar: educador ou gerente? São Paulo: Cortez, 2015.

PEREIRA, Anderson de Carvalho; RIBEIRO, Carme Sandra de Jesus. A culpabilidade pelo fracasso escolar e a interface com os problemas de aprendizagem em discurso. Educação \& Formação, Fortaleza, v. 2, n. 2, 2017, p. 95-110. 
SALDANHA, Manoela Atarão da Rocha; NODARI, Cristine Hermann; SALVAGNI, Julice. O papel do diretor na perspectiva do planejamento estratégico de uma gestão escolar. Revista de Gestão e Avaliação Educacional, Santa Maria, v. 6, n.12, 2017, p. 59-78.

SOUSA, Ana Carolina Braga de; PEREIRA, Arliene Stephanie Menezes. Paulo Freire, o andarilho da utopia: contribuições para a transformação social através da educação. Rev. Pemo, Fortaleza, v. 2, n. 2, 2020, p. 1-18.

SOUSA, João Moreira. Sistema educacional cearense. Recife: MEC/Inep, 1961.

YIN, Robert. Estudo de caso: planejamento e métodos. Porto Alegre: Bookman, 2001.

Francisca Risolene Fernandes é servidora pública municipal em Horizonte/CE, vinculada à Secretaria Municipal de Educação.

Orcid: https://orcid.org/0000-0002-9017-2142.

Endereço: Rua Manoel Nunes da Silva, 285/105 - 62880-016 - Horizonte - CE Brasil.

E-mail: profarisolenefernandes@gmail.com.

Francisca Genifer Andrade de Sousa é estudante no curso de Doutorado em Educação na Universidade Estadual do Ceará.

Orcid: https://orcid.org/0000-0001-8280-3250.

Endereço: Rua Central, 83 - 62860-000 - Pindoretama CE - Brasil.

E-mail: geniferandrade@yahoo.com.br.

Lia Machado Fiuza Fialho é professora no Programa de Pós-Graduação em Educação na Universidade Estadual do Ceará.

Orcid: https://orcid.org/0000-0003-0393-9892.

Endereço: Rua Aluísyo Soriano Aderaldo, 50/1402 - 60192-330 - Fortaleza - CE Brasil.

E-mail: lia fialho@yahoo.com.br.

Recebido em 15 de outubro de 2020.

Aceito em 12 de dezembro de 2020.

(c) (i) (3) $\Theta$ 